\title{
A Wireless Internet of Things Architecture Based on Mobile Internet
}

\author{
https://doi.org/10.3991/ijoe.v13i10.7745 \\ Bing Zhou \\ Jiaozuo University, Jiaozuo, China \\ $\mathrm{zbcn} 81 @ 126 . \mathrm{com}$
}

\begin{abstract}
In order to develop a valid wireless Internet of things system, a wireless Internet of things framework based on mobile Internet is designed. The architecture of the Internet of things determines the architecture of the Internet of things business platform. There is no uniform standard for the architecture of the Internet of things service platform. The Internet of things business platform is mostly in an isolated state. The platform uses the common information management platform of Internet websites to manage mobile internet. Combined with the technologies of perception, identification and network transmission in the Internet of things technology, it is a content management Web management information system with both $\mathrm{B} / \mathrm{S}$ (Browser/Server) and $\mathrm{C} / \mathrm{S}$ structure (Client/Server). The platform can operate anywhere, and can give full play to the processing capacity of the client PC, and greatly reduce the application server running data load. The experimental results show that compared with the centralized database system, in the same piece of redundant condition, when the test table data is greater than the 1 million and the concurrent number is 100 , the distributed database system has shorter concurrent query time and faster system response rate. Based on the above finding, it is concluded that wireless Internet of things technology based on mobile Internet will promote the development of the whole logistics industry and other related industries.
\end{abstract}

Keywords-Internet of things, mobile Internet, application platform, client

\section{Introduction}

The architecture of Internet of things has not yet formed a unified standard. At present, the industry is relatively recognized by a three-layer structure such as perception layer, network layer and application layer [1]. The architecture of the Internet of things determines the architecture of the Internet of things business platform. There is no uniform standard for the architecture of the Internet of things service platform [2]. In accordance with the Internet of things application platform business, it is divided into identity related business, information gathering business, anti-awareness services and ubiquitous services [3]. At present, the practical application of the research is similar intelligent logistics and intelligent transportation, while the Internet of things business platform is mostly in an isolated state [4]. Therefore, the current Internet of 
things users want to use a variety of business needs on a platform, which pushes the Internet of things business platform toward the direction of the ubiquitous business platform [5].

\section{Literature review}

At present, RFID is a mainstream technology with mature technology and extensive commercial applications. Today, the three mainstream technology standards systems in the international community include EPC Global, Ubiquitous ID Center and the ISO standard system [6]. At present, the research field of RFID technology mainly involves antenna type design, frequency selection, anti-collision isolation technology, security authentication and privacy protection [7]. According to the frequency, RFID technology can be divided into two major categories: $13.56 \mathrm{M}$ and 2.45 G. In the mainstream industry applications, such as banks, buses and other industries also adopted the 13.56 M RFID technology, which is the most mature RFID technology applications [8].

Currently, the networking application based on RFID has a better development in China, while the project oriented by government is the main force to promote the development of RFID. In this paper, a web based information publishing platform for Internet of things is designed [9]. RFID and WSN technology are used to realize the perception of Internet of things and achieve data acquisition [10]. WAMP tools are used to build the Internet of things server platform and complete the information through browser and remote client [11]. With the mobile Internet technology, this paper designs and implements the mobile Internet client platform and mobile client access which is connected with the Internet of things application platform [12]. The open interface provided by the WeChat platform is used to realize the interaction between the WeChat platform and the Internet of things application platform database, and complete the interconnection and intercommunication of the mobile Internet and the Internet of things [13].

\section{Method}

\subsection{Sensing and recognition section}

RFID is a contactless two-way communication switching, which uses radio frequency to communicate data for identification purposes. Generally, the short distance passive radio frequency card can replace the barcode because of its large amount of information, and the minimum identification distance of the passive RFID tag can reach tens of meters [14]. In a broad sense, a system that performs the basic functions of RFID consists of two parts: electronic tag and reader. As shown in figure 1, micro antennas that transmit radio frequency signals between tags and readers are integrated within the reader and electronic tag. 


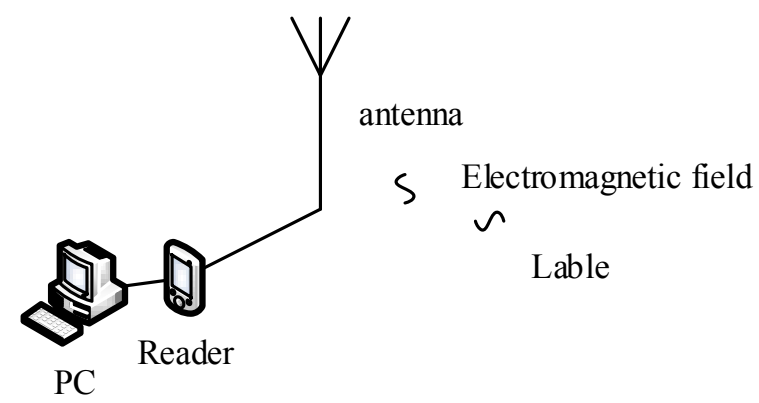

Fig. 1. Flexible multi-tier data processing and storage model based on Cloud Computing

Interface means the interface between the read and write device and the application computer. The RFID interface includes RS232, RJ45 (Ethernet), and 802.11 WLAN (wireless networks). In general, the RFID manufacturer provides the relevant interface software when it offers the product size to the user. But for the Internet of things platform system, the openness of the computer interface can be exploited because the manufacturer provides the software closeness limit. As long as the interface data stream is not encrypted two times, you can write the third -party software to obtain the relevant fields in the data stream of the interface, so as to obtain interactive information. A complete RFID application platform includes: RFID identification system, computer processing system and other functional auxiliary electronic information systems.

\subsection{Perceptual data storage and transmission}

Distributed Data Base (DDB) is a combination of network technology and traditional database technology. In recent years, the research focus in the field are: A fast algorithm for mining association rules based on distributed database, a secure mining algorithm based on reduced frequent pattern sets and association rules, dynamic serializable scheduling algorithm based on traffic flow [15]. As shown in Figure 2, a distributed database is a traditional database that is scattered across every node of the computer network. At the logical level, the databases that are distributed across the nodes belong to the same set of data. The management system based on the distributed database supports the establishment of distributed database, the use and maintenance of the database. It includes many functions, such as distributed local data management, distributed data scheduling management, communication between network data nodes and distributed data dictionary management. Compared to traditional database technology, distributed database mining technology combines with network communication technology, artificial intelligence technology, distributed computing, parallel computing technology and so on. It has become the trend of the current database technology development, and is the main characteristic direction of the database development in the Internet of things.

For the distributed database system, it is necessary to specify the site of the transaction execution when the allocation algorithm is used. By analyzing the query cost 


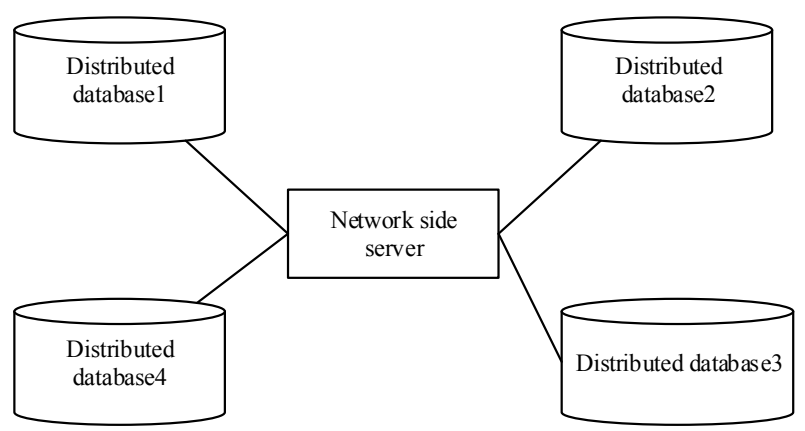

Fig. 2. Distributed database system

model of the distributed database, a transaction classification deployment strategy is proposed. Hierarchical clustering algorithm is used to classify query transactions and deploy similar transaction to the same site. In the process of clustering, query matrix and similarity matrix are constructed for query transaction, and the execution time of query transaction is reduced. The experimental results show that compared with the centralized database system, in the same piece of redundant condition, when the test table data is greater than the 1 million and the concurrent number is 100 , the distributed database system has shorter concurrent query time and faster system response rate.

\subsection{Information publishing platform of Internet of things}

The implementation of the B/S structure in the Internet of things information platform: As long as users install a browser (Browser) on the client, the server will also install the appropriate database software. In this structure, the user interface is fully implemented through the Web browser, and part of the transaction logic is implemented on the sweet side. However, the main transaction logic is implemented on the server side. The browser interacts with the data bank through the Web server.

The index of the Internet of things publishing platform is to reduce the workload of updating and maintaining the Internet of things information. By introducing the Internet of things database, the updating and maintenance of the Internet of things system is simplified to the standardized format uploading of the data, so as to speed up the information transmission of the Internet of things and keep the influence of the publishing system.

The task of system analysis is to determine the system requirements by analyzing the Internet of things, the perception layer, the information categories and functions, and collecting large amounts of information.

As shown in Figure 3, the front desk provides platform information access and query, according to functional categories, it mainly includes: Internet of things information list, display, list content, keyword inquiry and detailed information, and administrator user login. The background function is the main processing direction of the platform, including IOT category management, information content management, and background admin user logout. 
Table 1. The event table of the Internet of things publishing platform

\begin{tabular}{|c|c|c|c|c|}
\hline Events & Trigger & User source & Action & Response \\
\hline $\begin{array}{l}\text { New zone information for } \\
\text { workstation }\end{array}$ & $\begin{array}{l}\text { Add the zone } \\
\text { information }\end{array}$ & administrator & $\begin{array}{l}\text { Add zone infor- } \\
\text { mation }\end{array}$ & $\begin{array}{l}\text { Increased database area } \\
\text { information }\end{array}$ \\
\hline $\begin{array}{l}\text { Updated zone information } \\
\text { for workstation }\end{array}$ & $\begin{array}{l}\text { Modify the } \\
\text { zone infor- } \\
\text { mation }\end{array}$ & administrator & $\begin{array}{l}\text { Modify zone } \\
\text { information }\end{array}$ & $\begin{array}{l}\text { Updated database area } \\
\text { information }\end{array}$ \\
\hline $\begin{array}{l}\text { Deleted zone information } \\
\text { for workstation }\end{array}$ & $\begin{array}{l}\text { Delete the zone } \\
\text { information }\end{array}$ & administrator & $\begin{array}{l}\text { Delete zone } \\
\text { information }\end{array}$ & Deleted zone information \\
\hline $\begin{array}{l}\text { Newly increased zone } \\
\text { information for work- } \\
\text { station }\end{array}$ & $\begin{array}{l}\text { Add the zone } \\
\text { information }\end{array}$ & administrator & $\begin{array}{l}\text { Add zone infor- } \\
\text { mation }\end{array}$ & $\begin{array}{l}\text { Increased database zone } \\
\text { information }\end{array}$ \\
\hline $\begin{array}{l}\text { Updated zone information } \\
\text { for workstation }\end{array}$ & $\begin{array}{l}\text { Modify the } \\
\text { zone infor- } \\
\text { mation }\end{array}$ & administrator & $\begin{array}{l}\text { Modify zone } \\
\text { information }\end{array}$ & Updated zone information \\
\hline $\begin{array}{l}\text { Deleted zone information } \\
\text { for workstation }\end{array}$ & $\begin{array}{l}\text { Delete the zone } \\
\text { information }\end{array}$ & administrator & $\begin{array}{l}\text { Delete zone } \\
\text { information }\end{array}$ & Deleted zone information \\
\hline Browse all content & $\begin{array}{l}\text { View all con- } \\
\text { tent }\end{array}$ & everyone & View all content & $\begin{array}{l}\text { List header information in } \\
\text { the corresponding data } \\
\text { table }\end{array}$ \\
\hline Keyword view & $\begin{array}{l}\text { Query content } \\
\text { related to } \\
\text { keywords } \\
\end{array}$ & everyone & Query keywords & $\begin{array}{l}\text { List the key related title } \\
\text { information in the corre- } \\
\text { sponding data table }\end{array}$ \\
\hline Classification view & $\begin{array}{l}\text { Select a region } \\
\text { category }\end{array}$ & everyone & $\begin{array}{l}\text { Filter zone infor- } \\
\text { mation }\end{array}$ & $\begin{array}{l}\text { List relevant region header } \\
\text { information in the corre- } \\
\text { sponding data table }\end{array}$ \\
\hline $\begin{array}{l}\text { check the detail infor- } \\
\text { mation }\end{array}$ & View details & everyone & $\begin{array}{l}\text { Show detailed } \\
\text { entry information }\end{array}$ & $\begin{array}{l}\text { List the contents of the } \\
\text { corresponding information } \\
\text { in the data table }\end{array}$ \\
\hline log in system & $\begin{array}{l}\text { Fill in } \\
\text { username and } \\
\text { password }\end{array}$ & administrator & Login system & $\begin{array}{l}\text { Check the username and } \\
\text { password in the database }\end{array}$ \\
\hline Log off system & $\begin{array}{l}\text { Select logout } \\
\text { function }\end{array}$ & administrator & Logout system & logout \\
\hline
\end{tabular}

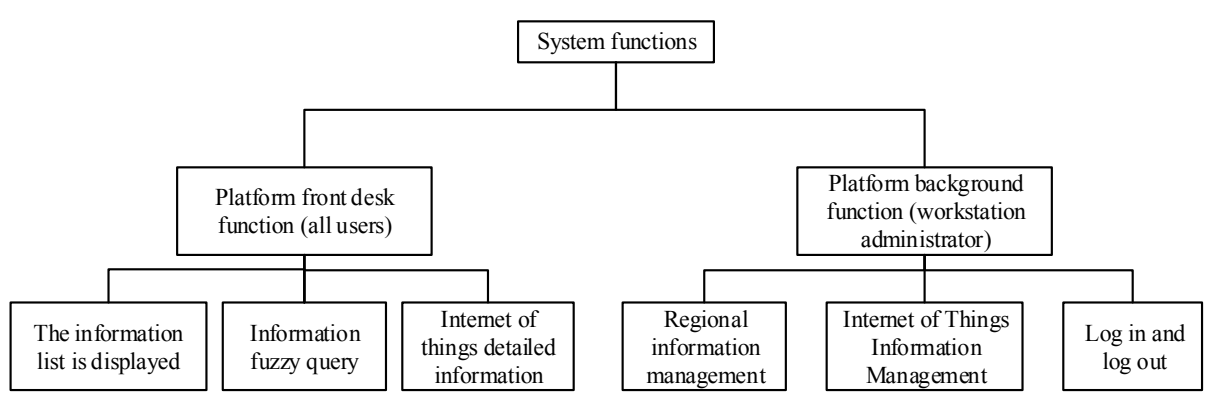

Fig. 3. Data table information flow of Internet of things distribution platform 


\section{Result and discussion}

The Internet of things platform perception system consists of wireless sensor network system and RFID system. Implementation details and testing procedures of two identification aware systems are described below.

\subsection{Wireless sensor network system test}

The implementation of CC2430 solutions in wireless sensor networks is presented in this paper. The sensor network is composed of frequency division multiple access. That is to say, nodes transmit their sensing information at different radio frequency points and occupy respective channel frequency points and Sink nodes respectively. By modifying their frequency points, sink nodes obtain the perception of each sub node by time division multiplexing.

The RFID system used in this paper is based on TI Corporation multi protocol transceiver chip S6700 and ISO/IEC15693 standard card reader. The ISO/1EC 15693 corresponding card is a contactless integrated circuit remote card (VICC), which has a further read distance than a near coupling card (PICC). The interface circuit is the communication circuit between the reader and the background database, and the common reader interface circuit has RS485, RS232 and other interfaces. This design uses the RS232 interface.

\subsection{Module testing of Internet of things publishing platform}

The Internet of things publishing platform mainly aims at the platform page structure and the logical jump design, and carries on the onstage page design around the backstage database. The main front page includes: landing pages, Internet information release, network information classification, see page and add / modify the shell surface, browse and other sectors, these different sectors constitute the networking platform.

As described in the previous section, all permissions control does not separate the administrator and user's browsing pages into two systems. The method used is to check all of the background scripts before they are executed. Whether there is user login information in the Session file management of server port. The administrator user enters the correct user name and password, and the system server puts the user information into the Session file, thus realizing the landing of the state. Editing and deleting functionality implementations are also using similar forms. In the edit and delete place, the conditional statement that determines the login status is inserted, and the feedback of the login status and function is realized.

\subsection{Results}

This chapter demonstrates the implementation of the sub module as shown in the previous section. First, the debugging process and the result display process of the 
perceptron layer wireless sensor network and the RFID system are described. The perception layer of the Internet of things consists of many sensors and recognition devices, and the perception of the physical world is varied. But the ultimate goal is to get the perception from the physical world into digital signals. By testing both the wireless sensor network and the RFID system, the physical signals are converted into digital quantities and uploaded to the control computer.

Then, in the application layer of the Web browser access to the Internet of things application platform, its database interface and background operations were analyzed and displayed. This is the $\mathrm{C} / \mathrm{S}$ structure module test based on the Internet server architecture. As the Internet of things information platform, browser / server mode is an indispensable way. Through the Web browser, the access data of the Internet of things server is continually updated, modified and deleted. This is the most convenient way for any remote control system or user to access the browser.

Finally, the basic functions are displayed for the Android client and WeChat public account of Mobile Internet side. This part caters to the rapid development and expansion of the mobile internet. With the gradual deepening of the commercial process of $4 \mathrm{G}$, more mobile Internet will emerge, and combine with the Internet of things to form an extended application.

\section{Conclusion}

The structure of the Internet of things application platform is introduced, and the common underlying system of two sensor layers is described in wireless sensor network and RFID system. By analyzing the technical characteristics and requirements of the Internet of things, network layer, application layer and network layer, the function and structure of a complete application platform are obtained.

In the next few years, the ubiquitous network society, which is realized through the Internet of things technology, will enter the actual application stage. In recent years, RFID technology will be used in the mainstream retail industry. With the development of this scene, a large number of objects will be addressable. Network access based on IP will promote the first large-scale applications of Internet of things. As long as the Internet of things has developed towards the existing route and properly regulated in the process of development, there will be broad prospects for the Internet of things, and even realize the third wave of the world's information industry".

\section{References}

[1] Kim, S., \& Na, W. (2015). Safe data transmission architecture based on cloud for internet of things. Wireless Personal Communications, 86(1), 1-14. Https://doi.org/10.1007/s1127 7-015-3063-1.

[2] Kim, N. S., Lee, K., \& Ryu, J. (2015). Study on internet of things based low-power wireless sensor network system for wild vegetation communities ecological monitoring. , 14(1), 159-173. Https://doi.org/10.9716/kits.2015.14.1.159. 
[3] Chelloug, S. A. (2015). Energy-efficient content-based routing in internet of things. Journal of Computer \& Communications, 03(12), 9-20. https://doi.org/10.4236/jcc.2015.31200 $\underline{2}$

[4] Yang, Y., \& Kanhua, Y. U. (2016). Construction of distance education classroom in architecture specialty based on internet of things technology. International Journal of Emerging Technologies in Learning, 11(5), 56. https://doi.org/10.3991/ijet.v11i05.5695

[5] Chang, J. Y. (2015). A distributed cluster computing energy-efficient routing scheme for internet of things systems. Wireless Personal Communications, 82(2), 757-776. https://doi.org/10.1007/s11277-014-2251-8

[6] Ghadi, M., Laouamer, L., \& Moulahi, T. (2016). Securing data exchange in wireless multimedia sensor networks: perspectives and challenges. Multimedia Tools \& Applications, 75(6), 3425-3451. https://doi.org/10.1007/s11042-014-2443-y

[7] Khan, F. (2016). Multi-comm-core architecture for terabit-per-second wireless. IEEE Communications Magazine, 54(4), 124-129. https://doi.org/10.1109/MCOM.2016.74522 $\frac{76}{H}$

[8] Hao, F., Jiao, M., Min, G., \& Yang, L. T. (2015). Launching an efficient participatory sensing campaign: a smart mobile device-based approach. Acm Transactions on Multimedia Computing Communications \& Applications, 12(1s), 18. https://doi.org/10.1145/28081 98

[9] Yan, Z., Lee, J. H., Lee, X., \& Park, Y. J. (2015). Utilizing the domain name system for scalable and secure named data networking. Wireless Personal Communications, 84(3), 2135-2149. https://doi.org/10.1007/s11277-015-2537-5

[10] Fisher, R., Ledwaba, L., Hancke, G., \& Kruger, C. (2015). Open hardware: a role to play in wireless sensor networks?. Sensors, 15(3), 6818. https://doi.org/10.3390/s150306818

[11] Chen, Y., Zhou, J., \& Guo, M. (2016). A context-aware search system for internet of things based on hierarchical context model. Telecommunication Systems, 62(1), 77-91. https://doi.org/10.1007/s11235-015-9984-x

[12] Ibrar Yaqoob, Ejaz Ahmed, Ibrahim Abaker Targio Hashem, Abdullah Gani, Muhammad Imran, \& Mohsen Guizani. (2017). Internet of things architecture: recent advances, taxonomy, requirements, and open challenges. IEEE Wireless Communications, 24(3), 10-16. https://doi.org/10.1109/MWC.2017.1600421

[13] Hao, X. C., Xin, M. J., \& Ru, X. Y. (2015). Eapor: a distributed, energy-aware topology control algorithm based path-obstacle-remove model for wsn. Wireless Personal Communications, 80(2), 1-22. https://doi.org/10.1007/s11277-014-2034-2

[14] Lu, Z., Li, Y., \& Fu, T. (2015). Intelligent wind-speed monitoring system based on the zigbee wireless network. International Journal of Online Engineering, 11(1), 57. https://doi.org/10.3991/ijoe.v11i1.4364

[15] Pencheva, E., \& Atanasov, I. (2016). Engineering of web services for internet of things applications. Information Systems Frontiers, 18(2), 277-292. https://doi.org/10.1007/s1079 $\underline{\text { 6-014-9532-3 }}$

\section{Author}

Bing Zhou is with School of Information Engineering, Jiaozuo University, Jiaozuo 454000, China (zbcn81@126.com).

Article submitted 12 September 2017. Published as resubmitted by the author 18 October 2017. 